\title{
Perception of Urban Retailing Environments: An Empirical Analysis of Consumer Information and Usage Fields
}

\author{
HARRY TIMMERMANS, ROB VAN DER HEIJDEN and HANS WESTERVELD*, \\ Eindhoven, The Netherlands
}

\begin{abstract}
This article reports on an empirical analysis of consumer information and usage fields in the city of Eindhoven. The main purposes of this study are to investigate the distance, sectoral and directional biases of these fields, to analyse whether the degree of biases is related to personal characteristics of consumers and to identify the factors of the basis on which a model which predicts the probability that a shopping centre will be known by consumers can be developed. The findings of the study suggest that strong distance, sectoral and directional biases are present in the information and usage fields of consumers and that no systematic relationships exist between these characteristics of information and usage fields and personal variables of consumers. Finally, the present studies suggests that a model which describes the formation of consumer choice sets should include spatial factors such as distance, size, intervening opportunities and direction towards the city centre.
\end{abstract}

\section{Introduction}

Recently, SHEPHERD and THOMAS (1980) have advocated that the analysis of consumer information fields constitutes one of the research priorities in the short term in retail geography. The significance of the study of consumer information fields stems from two potential and interlocking contributions which this kind of analysis might make to the development of geographic theory and model building. Firstly and most importantly, the analysis of consumer information fields might contribute to the solving of the problem of the choice set formation, which is one of the most important problems of existing spatial choice models. Spatial choice models generally aim at predicting the probability that an individual will choose an alternative from among all possible alternatives, given the location of the individual and

*Postal address: University of Technology, Department of Architecture, Building \& Planning, P.O. Box $513 \mathrm{HG}$ II. $25,5600 \mathrm{MB}$ Eindhoven, The Netherlands.

Harry Timmermans is a lecturer in urban and quantitative geography at the University of Technology, Eindhoven. Rob van der Heijden and Hans Westerveld are students at the same institute. the locations and attributes of the set of alternatives. Most operational spatial choice models assume that individuals have all alternatives which are present in their environment in their choice sets (e.g. RUSHTON, 1969;, RECKER and KOSTYNIUK, 1978). However, this assumption has been criticised by several authors (e.g. PIRIE, 1976; TIMMERMANS, 1979; MACLENNAN and WILLIAMS, 1979, 1980). In addition, empirical evidence is accumulating which shows that the number and kinds of alternatives which individuals have vary systematically with personal, societal and environmental factors (e.g. DIX, 1977; HEGGIE, 1977). The implication is that the formation of individual choice sets should be made an integral part of models which attempt to predict spatial choice behaviour. Very recently, there have been some initial attempts to link the formation of choice sets mathematically with spatial search and learning processes (BEAVON and HAY, 1977; SMITH et al., 1979; MEYER, 1980), but none of this work has succeeded in providing an approach which may be used in an applied context and encompasses most of the relevant variables defining choice sets. While such an approach might still be a long way ahead, there is, nevertheless, a vast amount of empirical 
research which suggests that the formation of choice sets is based on the perceived availability of alternatives rather than on their actual availability (HORTON and REYNOLDS, 1969, 1971; ALDSKOGIUS, 1977; HANSON, 1976; POTTER, 1979). It is especially in this respect that the analysis of consumer information fields may provide the stepping stones to the development of mathematical models on the formation of choice sets. Secondly, the analysis of consumer information might result in a better understanding of the ways in which people perceive their environment. As such, the results of this type of analysis might contribute to the development of theory regarding the perception of urban phenomena. The refinement of existing theoretical notions on urban environmental perception and cognition awaits further empirical results on the factors influencing the perception and the relationship between perception and personal characteristics of individuals. As POTTER (1979) has argued, such research findings are an essential prerequisite for planners who attempt to assess the likely impact of new developments on different subgroups of individuals.

Studies on perception in human geography have been primarily concerned with the perception of 'clues' in an urban setting (e.g. GOLLEDGE, 1978; GOLLEDGE and SPECTOR, 1978), regional images (e.g. GOULD and WHITE, 1968, 1974; JONES, 1978; PALMER et al., 1977; PALMER, 1978) and perception in relation to the intra-urban migration process (e.g. ADAMS, 1969; RROWN and MOORE, 1970; JOHNSTON, 1971, 1972; DONALDSON and JOHNSTON, 1973; DONALDSON, 1973). The study of the perception of urban retailing environments in terms of consumer information fields, which constitutes the subject matter of the present article, is to the authors' knowledge restricted to work by HANSON (1976, 1977), SMITH (1976) and POTTER (1976a, b, 1977 a , b , c, 1978, 1979), although some studies exist on perceptual maps of supermarket locations (MACKAY and OLSHAVSKY, 1975; MACKAY et al., 1975; OLSHAVSKY and MACKAY, 1975) and cognitive dimensions of shops and shopping centres (DOWNS, 1970; BURNETT, 1973; HUDSON, 1974; SINGSON, 1975; SPENCER, 1978, 1980; BLOMMESIEIN et al., 1980; TIMMERMANS et al., 1981). This limited interest in consumer information fields is clearly in contrast with the vast amount of research effort which has been paid to the modelling of spatial consumer behaviour. Evidently, therefore, more replications are needed to allow the development of mathematical models on the formation of choice set and to get somewhat more insight into the generalizability of previous research findings.

This article presents the main findings of a detailed analysis of biases in consumers' information and usage fields within the city of Eindhoven. In addition, some results on the specific nature of such fields and their relationship with socio-economic variables of consumers will be presented. At the outset, the definition and measurement of consumer information and usage fields will be discussed briefly. Next, the main findings of the empirical analysis will be presented. The article concludes by discussing the implications of the results of the present analysis to the development of models on the formation of choice sets and the refinement of existing theoretical notions on the perception of urban phenomena.

\section{The Definition and Measurement of Information and Usage Fields}

POTTER (1979) has defined the information field of a consumer as the zone which includes all the retail centres about which he possesses knowledge, irrespective of whether they are used or not in the conduct of his shopping. Similarly, the usage field of a consumer is defined as the zone which includes all the retail centres which he patronises in the course of his shopping activities. It is assumed that a consumer's spatial information field is developed through a search and learning process. When a newcomer arrives in an area he is confronted with a set of potential alternatives where he can shop. In the beginning, he will probably only know the local shopping centre and the town centre but gradually he will know more potential destinations through his trips in the city, advertisements, etc. until a more or less stable information field results. This field will include only certain elements of his actual environment. At the same time, the consumer will test and compare the centres within his information field in the light of his personal wants and needs. Again, through a search and learning process, a more or less stable set of shopping centres will be retained to conduct his shopping activities. This set constitutes the consumer's spatial usage field. The consumer's information and usage field may change due to changes in his retailing environment or to changes in his daily life such as a new job or a new home.

In order to describe the spatial information and usage fields of consumers, measurements have to be 
made of certain characteristics of these fields. Several methods of obtaining these data for information fields exist. POTTER (1979), for example, has used a graphical method, asking respondents to indicate on a base map all of the shopping places about which they possessed information. This method might be criticised in that its results might be biased due to the graphical abilities of respondents. For example, MACKAY (1976) argued that graphical methods confound artistic abilities and motor skills with cognitive recall.

On the other hand, since the analysis is primarily concerned with the number and the name of the centres about which the respondents hold information and not with the accuracy of the locational patterns of the shopping centres on these mental maps, it is difficult to see why possible graphical bias would systematically alter the findings of a study on consumer information and usage fields. An alternative way of eliciting data on information fields is to ask respondents to mark on a scale of familiarity their level of familiarity with a set of prespecified shopping places (HANSON, 1977). While this method avoids problems of recall error which might occur in straightforward asking, its results might nevertheless be biased due to the fact that the respondents might be confused by the labelling of the places. It is necessary, therefore, to specify the shopping places as clearly as possible by using combinations of names, addresses, maps and photographs. Whereas different methods thus have been used to identify consumer information fields, the measurement of consumer usage fields proceeds almost invariably by asking respondents to name all of the shopping places which they actually visit. Recall bias might be minimised by introducing some check mechanisms in the questionnaire.

Having gathered this information, the measurement of consumer information and usage fields involves the use of a number of summary statistics to describe their characteristics. Firstly, the total number of centres constituting the information and usage fields may be enumerated. This results in an information and usage total. Secondly, the mean distance from the respondent's home to these centres may be calculated. Finally, some measures of the directional and sectoral bias may be derived. The mean distance measure gives an indication of the distance bias; it describes the degree to which consumers possess more information about nearby shopping centres than about more distant centres. Directional bias describes the degree to which the information and usage fields are oriented towards a particular direction from the consumer's place of residence. Sectoral bias describes the degree to which the information and usage fields are structured along a single axis through the consumer's place of residence.

In this study, the approach which has been suggested by BROWN and HOLMES (1971) within an intraurban migration context was adopted with minor modifications to measure distance, directional and sectoral biases. The approach has the advantage that the distance, directional and sectoral bias of each consumer's information and usage fields are preserved, which implies that these individual distributions can be combined to generate an aggregate distribution reflecting the spatial biases of the total sample. It involves the rotation and translation of the vectors linking the consumers' place of residence to the city centre until they coincide with a common axis emanating from the city centre and occupy a common point on this common axis. The shopping centres constituting a consumer's information or usage field are rotated and translated to the same degree and in the same directions as the consumer's place of residence had been rotated and translated, which implies that the distance, directional and sectoral relationships of the original distribution are retained. Next, the spatial properties of each distribution are identified by the standard ellipse technique, which finds the elliptical function which best fits the point distribution and yields a number of summary statistics which are derived from this function and describe the spatial biases in the distribution. The standard radius from the mean centre describes the average dispersion of the distribution from its mean centre, thereby providing another measure of the distance bias: the less the standard radius, the greater the distance bias. The coefficient of circularity equals the ratio of the length of the minor axis of the ellipse to that of the major axis. It provides information about the sectoral bias of the distribution: as the coefficient goes from zero to one the degree of sectoral bias decreases. The angle of rotation describes the angle between the major axis of the ellipse and the base axis. This measure gives an indication of the degree of directional bias. An angle of rotation of $0^{\circ}$ or $180^{\circ}$ is an indication of directional bias, respectively, towards or away from the city centre. The interpretation of directional bias might be assisted by examining the distance from the consumer's place of residence to the mean centre of the distribution as well as the direction of the mean centre (distance and direction of displacement). A strong directional bias towards the city centre is in- 
dicated by a situation in which both the angle of rotation and the angle of displacement are close to zero and the distance of displacement is negative. A strong directional bias away from the city centre exists when the angle of rotation is close to $180^{\circ}$, the angle of displacement is close to $0^{\circ}$ and the distance of displacement is positive.

\section{The Empirical Research}

\section{Study area, sample and methodology}

The study area selected for the empirical analysis of consumer information and usage fields was the city of Eindhoven. The city of Eindhoven has approximately 200,000 inhabitants. To measure the information and usage fields, 24 shopping opportunities were selected within the city (Figure 1). Most of these opportunities are located in the District of Woensel because all of the sample respondents were located within this district. The shopping opportunities varied considerably in terms of their size, morphology, age and lay-out attributes.

The data on the information and usage fields were obtained through personal interviews. A total of 194 respondents participated in the survey. These 194 respondents constitute a probability sample selected by a cluster design from the households in the Woensel area. The total sample consisted of 10 cluster points. The interviewers collected a variety of information from the respondents, but for the following analysis only some data are particularly relevant. Firstly, each respondent was asked to specify his or her degree of familiarity with the preselected set of 24 shopping opportunities on a five-point rating scale with anchor points 'completely unfamiliar' and 'extremely familiar'. Secondly, all of the respondents were asked to name the shopping centres they patronize in conducting their shopping activities for daily as well as for nondaily goods. Finally, respondents were asked about some personal characteristics. These characteristics include car ownership, car use for shopping trips, length of residence, age, income and education. Table 1 gives the frequency distribution of the sample population by these personal characteristics. It shows that data of people of all categories of these characteristics were available.

The empirical analysis consisted of three parts. Firstly, summary statistics about information and usage totals, mean distance, and distance, directional and sectoral biases in information and usage fields were calculated. Secondly, it was investigated whether these summary statistics were systematically related

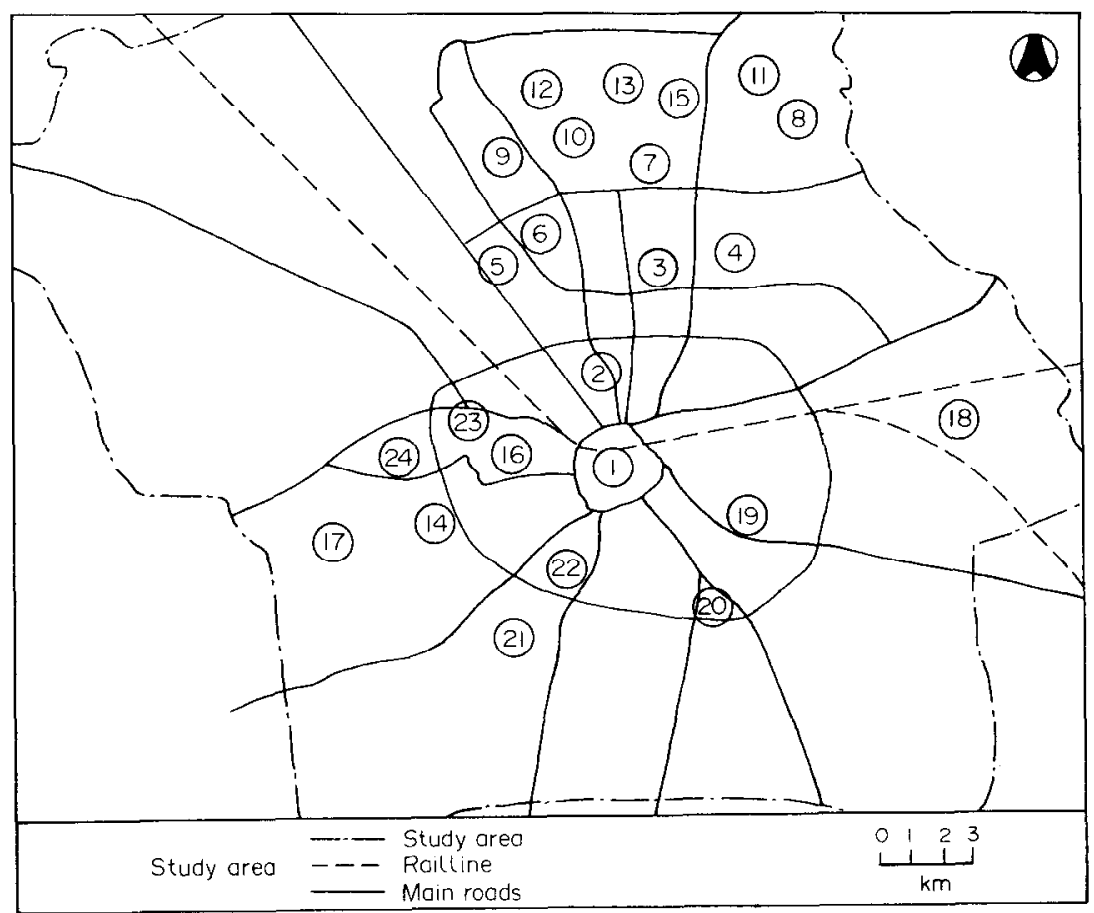

Figure 1. 
to the selected personal characteristics of the consumers. This analysis involved the calculation of separate $t$-tests for all pairs of categories of the independent variable. It is acknowledged that this procedure involves the problem that the probability of at least one significant result will be greater than the chosen significance level, because the $t$-tests are mutually dependent. On the other hand, the calculation of separate $t$-tests has the advantage that the researcher receives more information.

Thirdly, it was analysed whether information totals were related to a number of spatial factors. Together, the results of the empirical analysis indicate possibilities for formulating a mathematical model which predicts the probability that a consumer will possess knowledge about a shopping centre, giving the score of this centre on a number of relevant attributes.

Table 1. Characteristics of the sample respondents

\begin{tabular}{|c|c|c|}
\hline & $\begin{array}{l}\text { Total number of } \\
\text { respondents }\end{array}$ & $\begin{array}{l}\text { Percentage of } \\
\text { total sample }\end{array}$ \\
\hline \multicolumn{3}{|l|}{ Car ownership } \\
\hline Yes & 165 & 85.05 \\
\hline No & 29 & 14.95 \\
\hline \multicolumn{3}{|l|}{ Car use } \\
\hline Never & 31 & 15.97 \\
\hline Infrequently & 54 & 27.84 \\
\hline Regularly & 54 & 27.84 \\
\hline Always & 55 & 28.35 \\
\hline \multicolumn{3}{|c|}{ Length of residence } \\
\hline$<2$ years & 75 & 38.66 \\
\hline $2-5$ years & 19 & 9.79 \\
\hline$>5$ years & 100 & 51.55 \\
\hline \multicolumn{3}{|l|}{ Age } \\
\hline$<25$ years & 19 & 9.79 \\
\hline $25-40$ years & 72 & 37.12 \\
\hline $40-60$ years & 86 & 44.33 \\
\hline$>60$ years & 17 & 8.76 \\
\hline \multicolumn{3}{|l|}{ Income } \\
\hline Low & 30 & 15.46 \\
\hline Medium & 84 & 42.78 \\
\hline High & 28 & 14.43 \\
\hline Not known & 52 & 27.33 \\
\hline \multicolumn{3}{|l|}{ Education } \\
\hline Low level & 114 & 58.76 \\
\hline Medium level & 67 & 34.54 \\
\hline High level & 13 & 6.70 \\
\hline
\end{tabular}

\section{Findings}

Information and usage totals. The summary statistics about the information and usage fields are given in Table 2. This table shows that the information totals range from one to seventeen. However, $92.8 \%$ of the respondents possess information about only one to ten shopping centres. The mean of the distribution is 6.41 , the mode is 5-6. Thus, the frequency distribution shows that the information is markedly skewed towards lower information totals, a finding which is similar to Potter's results (POTTER, 1979). Table 2 also provides summary statistics about consumer usage fields. It shows that consumers generally use fewer shopping centres than the total they know about. The usage totals range from one to seven. However, again the frequency distribution is skewed toward lower usage totals: $78.8 \%$ of the respondents use less than six shopping centres, the mean of the distribution is 4.58 and the mode is 5 .

Mean information and usage totals were computed for subgroups of respondents according to their personal characteristics (Tables 3 and 4). In addition, the statistical significance of differences in mean information and usage totals were tested by a series of pairwise $t$-tests. Table 3 shows that there is no systematic relationship between mean information totals and the set of selected personal characteristics. Only onc of the $t$-values is significant beyond the $5 \%$ probability level; namely the one associated with the difference between the medium and high income groups. However, unlike the results of previous research, no systematic relationships between information totals and car ownership, car use, age, length of residence and social class variables like income and education were established. Table 4 gives the results for the usage totals. Generally, the results for the usage totals are very similar to those obtained for the information totals. That is, no systematic relationships between usage totals and personal characteristics of consumers were established. Only four $t$-values were significant beyond the $5 \%$ probability level. It was found that consumers living in the area for less than two years use significantly less shopping centres than consumers who live in the area for more than two years. In addition, the analysis of usage fields suggests that low and medium income groups use more shopping centres than the high income group. Finally, the 25-40 age group uses significantly less shopping centres than the $40-60$ age group.

Mean distance of centres and standard radius. Two further characteristics of information and usage 
fields are the mean distance of a consumer's place of residence to the centres about which he possesses information or which he uses in the conduct of his shopping and the corresponding standard radius. These measures give an indication of the distance bias in consumer information and usage fields.

Table 5 gives the overall mean distance of all centres comprising the information and usage fields of the respondents. Table 5 shows that the overall mean distance of the centres comprising the consumers' information fields is $2.34 \mathrm{~km}$, whereas the overall mean distance of the centres comprising the usage fields is only $1.77 \mathrm{~km}$. This result suggests that consumers tend to use the nearer shopping centres of their information fields. Although consumers possess knowledge about more distant shopping centres, they tend to disregard the more distant centres in the conduct of their shopping.

The mean distance of centres comprising the consumers' information and usage fields was also considered in connection with the set of personal characteristics of the respondents. The results are shown in Tables 3 and 4 . In general, no consistent pattern emerges from the analysis. Most of the $t$-values were insignificant beyond the $5 \%$ probability level. At a more detailed level, respondents owning a car tend to possess knowledge about more distant shopping centres and they also tend to use more distant centres. However, the differences in mean distance of centres comprising the information and usage fields are statistically insignificant beyond the $5 \%$ probability level. Respondents who use a car regularly or always in the conduct of their shopping possess knowledge about and use more distant shopping centres than respondents who never or infrequently use a car in the conduct of their shopping. This tendency is illustrated by the significant $t$-values of the differences in the mean distance of centres for the two groups. With regard to length of residence, Tables 3 and 4 indicate that newcomers tend to possess knowledge about and use more distant shopping centres. This result might be explained by the fact that these respondents still use shopping centres from other parts of the city from where they moved. Tables 3 and 4 also illustrate that younger people tend to use more distant shopping centres than the older people and that, consequently, they possess more knowledge of the more distant centres. The effects of income and education on the mean distance of information and usage fields are rather inconsistent. On the one hand, there is some indication that the mean distance of the information and usage fields of higher income groups is greater than that of the lower income groups but this result is not substantiated by the other operationalization of the social class variable.

Examination of Table 3 shows that no systematic

Table 2. Frequency distribution of respondents by information and usage total

\begin{tabular}{|c|c|c|c|c|}
\hline \multirow[b]{2}{*}{$\begin{array}{l}\text { Number of } \\
\text { centres }\end{array}$} & \multicolumn{2}{|c|}{ Information total } & \multicolumn{2}{|c|}{ Usage total } \\
\hline & $\begin{array}{l}\text { Total number } \\
\text { of respondents }\end{array}$ & $\begin{array}{c}\text { Percentage } \\
\text { of respondents }\end{array}$ & $\begin{array}{l}\text { Total number } \\
\text { of respondents }\end{array}$ & $\begin{array}{c}\text { Percentage } \\
\text { of respondents }\end{array}$ \\
\hline 1 & 3 & 1.6 & 3 & 1.5 \\
\hline 2 & 3 & 1.6 & 7 & 3.6 \\
\hline 3 & 11 & 5.7 & 28 & 14.4 \\
\hline 4 & 30 & 15.5 & 51 & 26.3 \\
\hline 5 & 34 & 17.5 & 64 & 33.0 \\
\hline 6 & 34 & 17.5 & 23 & 11.9 \\
\hline 7 & 22 & 11.3 & 18 & 9.3 \\
\hline 8 & 21 & 10.8 & - & - \\
\hline 9 & 14 & 7.2 & - & - \\
\hline 10 & 8 & 4.1 & - & - \\
\hline 11 & 5 & 2.6 & - & - \\
\hline 12 & 4 & 2.1 & - & - \\
\hline 13 & 1 & 0.5 & - & - \\
\hline 14 & - & - & - & - \\
\hline 15 & 2 & 1.0 & - & - \\
\hline 16 & 1 & 0.5 & - & - \\
\hline 17 & 1 & 0.5 & - & - \\
\hline
\end{tabular}




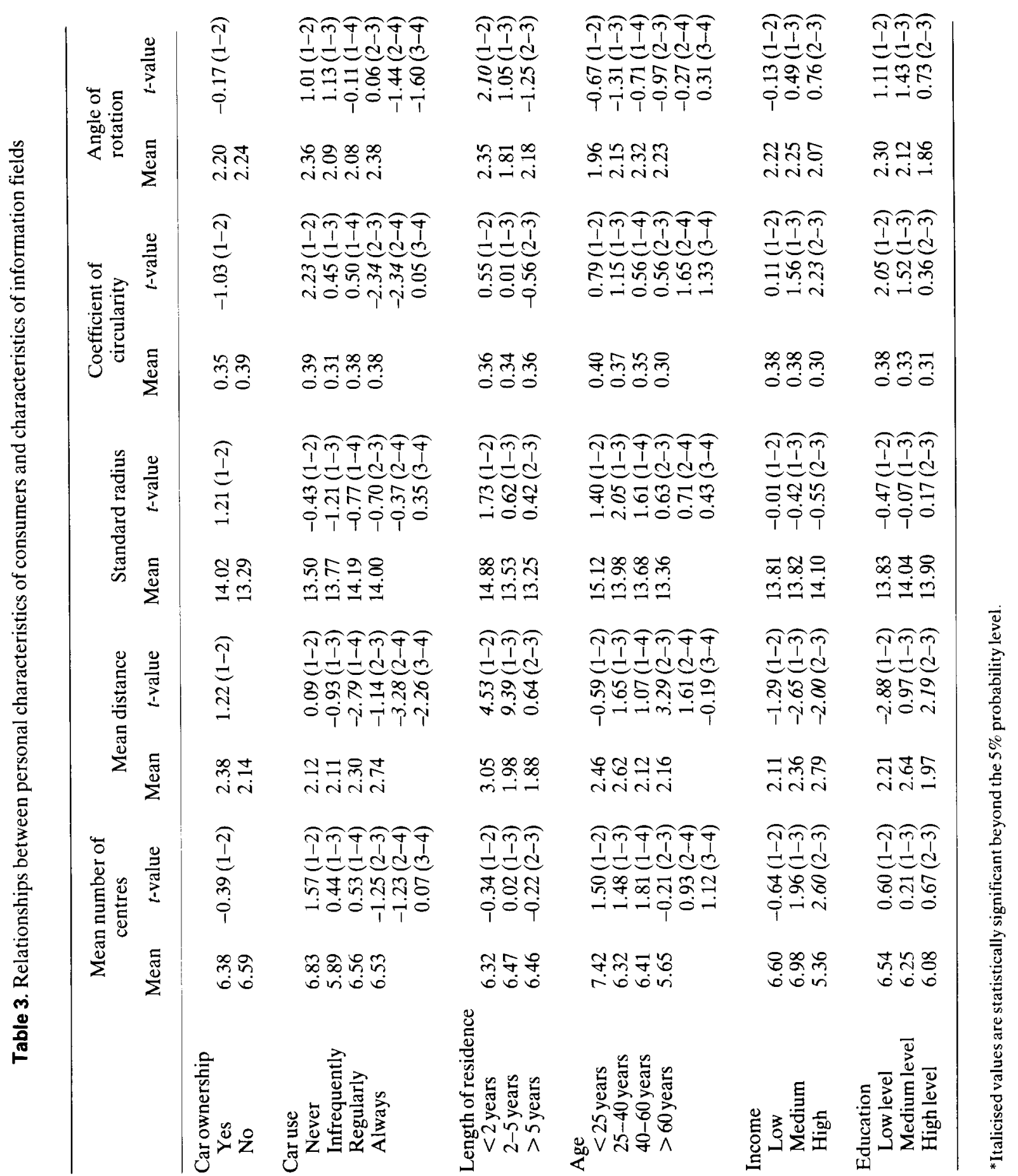




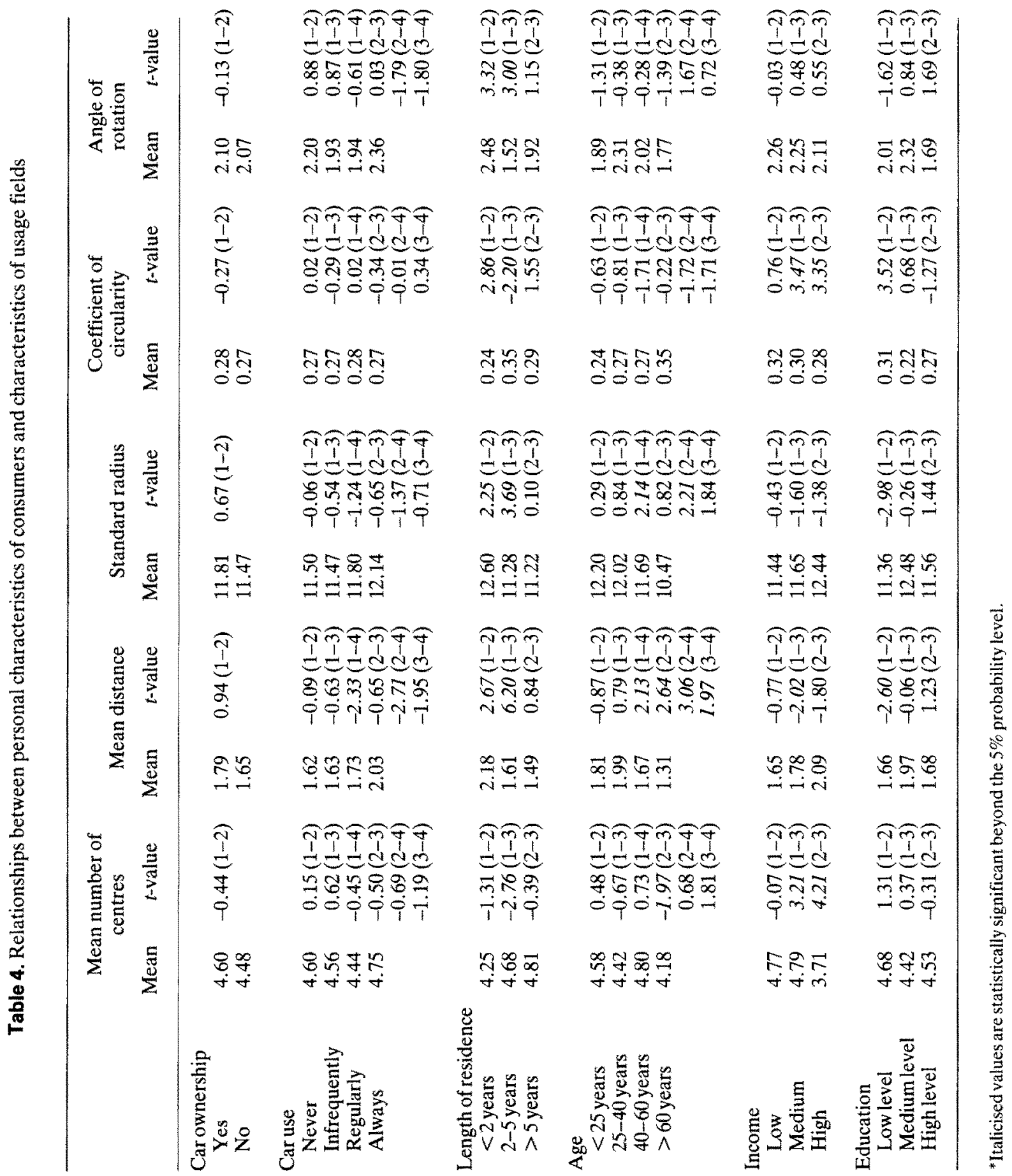


Table 5. Characteristics of information and usage fields

\begin{tabular}{lcc}
\hline & Information fields & Usage fields \\
\hline Mean number of centres & 6.41 & 4.58 \\
Range & $1-17$ & $1-7$ \\
Mean distance & 2.34 & 1.77 \\
Means standard radius & 13.91 & 11.76 \\
Mean coefficient of circularity & 0.36 & 0.27 \\
Mean angle of rotation & 2.21 & 2.09 \\
\hline
\end{tabular}

pattern emerges in terms of the relationship between personal characteristics and the standard radius of the information fields. Only one $t$-value, that for the difference between the 25-40 and 40-60 age groups, is significant beyond the $5 \%$ probability level. Table 4 shows that more $t$-values are statistically significant for the standard radius of the usage fields, but again no systematic effects can be identified. Consequently, it must be concluded that the analysis suggests that the information and usage fields of consumers are biased towards the nearer shopping centres, but that the degree of bias shows no systematic relationships with the set of personal characteristics of consumers.

Coefficient of circularity. The coefficient of circularity measures the degree of sectoral bias in the information and usage fields of consumers. Table 5 shows that the mean coefficient of circularity of the information fields is 0.36 and that the corresponding value of the usage fields is 0.27 . Consequently, the information and usage fields of consumers are sectorally biased, with the degree of sectoral bias of the usage fields exceeding that of the information fields. Tables 3 and 4 again indicate that in general no systematic relationships can be identified between the coefficient of circularity and the personal characteristics of consumers. With regard to the usage fields, the coefficient of circularity tends to decrease as the income of the consumer rises; the remaining profiles show no consistent and statistically significant pattern.

Angle of rotution. The angle of rotation measures the degree of directional bias in the information and usage fields of consumers. Table 5 shows that the mean angle of rotation of the information fields is 2.21 , whereas the mean angle of rotation of the usage fields is 2.09 . Thus, the information and usage fields of the respondents both show a directional bias towards the city centre. Examination of the values of the pairwise $t$-tests, as shown in Tables 3 and 4 , again suggests that differences in angle of rotation of information and usage fields are not systematically related to the set of personal characteristics of consumers.

The effect of size and distance. The results which have been obtained so far suggest that characteristics of information and usage fields are not systematically related to socio-economic variables. In order to investigate whether the size of the shopping centre and the distance from the respondent's place of residence to the shopping centre are related to characteristics of information and usage fields, the shopping centres were classified into four mutually exclusive categories. This classification was accomplished by using a non-hierarchical clustering routine. The input for the analysis was formed by data on the frequency of the occurrence of eighty retailing functions in each shopping centre. In addition, a table was constructed with four categories $(<0.8 ; 0.8-2.5 ; 2.5-4.5 ;>4.5$ $\mathrm{km}$ ), showing the distance separation between the respondents and each shopping centre.

Table 6 gives the proportion of all possible shopping centres falling within a combination of size and distance separation about which consumers possess information and which consumers patronise in the conduct of their shopping. Examination of Table 6 suggests that both size and distance are influential to the construction of information and usage fields, although some interaction effects are apparent. In general, Table 6 shows that the proportion of shopping centres about which consumers possess information tends to decrease as the distance separation between the respondent's place of residence and the shopping centres increases, whereas this proportion increases as the size of the shopping centres increases. In addition, Table 6 indicates that similar effects hold for the usage field of consumers. 
Table 6. Proportion of respondents knowing/using shopping centres, defined as combinations of size and distance separation

\begin{tabular}{lcccc}
\hline & \multicolumn{4}{c}{ Distance (km) } \\
Functional level & $<0.8$ & $0.8-2.5$ & $2.5-4.5$ & $>4.5$ \\
\hline A. Information fields & & & & \\
$\quad$ I (lowest) & 0.68 & 0.18 & 0.13 & 0.15 \\
II & 1.00 & 0.27 & 0.10 & 0.05 \\
III & 1.00 & 0.97 & 0.57 & 0.05 \\
IV (highest) & 1.00 & 0.91 & 0.91 & 0.97 \\
B. Usage fields & & & & \\
I (lowest) & 0.65 & 0.13 & 0.02 & 0.00 \\
II & 1.00 & 0.21 & 0.02 & 0.00 \\
III & 1.00 & 0.97 & 0.70 & 0.00 \\
IV (highest) & 1.00 & 0.76 & 0.83 & 0.92 \\
\hline
\end{tabular}

\section{Conclusions}

Throughout this study the aims have been to examine biases in the information and usage fields of consumers, to investigate whether the degrees of biases are related to socio-economic and spatial variables and to identify the variables on the basis of which a model on the formation of choice sets might be developed.

The present study suggests that consumer usage and information fields show a considerable degree of distance, sectoral and directional bias. Consumers tend to use and possess more information about the nearer shopping centres, about centres along major networks in their city and about centres in the direction of the city centre. Distance, intervening opportunity and directional effects are present in the information and usage ficlds of consumers. This result is to a substantial degree in agreement with the results of previous studies, in different cities and societal circumstances. However, unlike previous results, in the present study no systematic relationships were established between some characteristics of consumer information and usage fields and a set of selected personal characteristics of consumers. On the other hand, the analysis has indicated that the size and distance variables are related to the information-gathering process of consumers and, consequently, to the shopping centres people visit to buy certain goods. Consequently, it might be relevant to base models which predict the probability that consumers will possess information about a shopping centre on spatial factors such as size, dis- tance and intervening opportunities rather than on factors which specify personal characteristics of consumers. Future research will learn whether such models can be developed successfully.

\section{References}

ADAMS, J. S. (1969) Directional bias in intra-urban migration, Econ. Geogr., 45, 302-323.

ALDSKOGIUS, H. (1977) A conceptual framework and a Swedish case study of recreational behavior and environmental cognition, Econ. Geogr., 53, 163-184.

BEAVON, K. S. O. and HAY, A. (1977) Consumer choice of shopping centre: a hypergeometric approach, Envir. Planning A, 9, 1375-1393.

BLOMMESTEIN, H., NIJKAMP, P. and VEENENDAAL, W. VAN (1980) Shopping perceptions and preferences: a multidimensional attractiveness analysis of consumer and entrepreneurial attitudes, Econ. Geogr., 56, 155-174.

BROWN, L. A. and HOLMES, J. (1971) Scarch bchavior in an intra-urban migration context: a spatial perspective, Envir. Planning A, 3, 307-327.

BROWN, L. A. and MOORE, E. G. (1970) The intraurban migration process: a perspective, Geogr. Ann. B, 52, 1-13.

BURNETT, P. (1973) The dimensions of alternatives in spatial choice processes, Geogrl Anal , 5, 181-204.

DIX, M. C. (1977) Report on investigations of houschold travel decision making behaviour, Working Paper No. 27. Transport Studies Unit, University of Oxford, Oxford.

DONALDSON, B. (1973) An empirical investigation into the concept of sectoral bias in the mental maps, search spaces and migration patterns of intra-urban migrants, Geogr. Ann. B, 55, 13-33.

DONALDSON, B. and JOHNSTON, R. J. (1973) Intraurban sectoral mental maps: further evidence from an extended methodology, Geogrl Anal., 5, 45-54. 
DOWNS, R. M. (1970) The cognitive structure of an urban shopping centre, Envir. Behav, 2, 13-39.

GOLLEDGE, R. G. (1978) Learning about urban environments, In: Making Sense of Time, T. Carlstein, D. Parkes and N. Thrift (Eds.). Edward Arnold, London.

GOLLEDGE, R. G. and SPECTOR, A. (1978) Comprehending the urban environment, Geogrl Anal., 10, 403-427.

GOULD, P. and WHITE, R. R. (1968) The mental maps of British school leavers, Reg. Stud., 2, 161-182.

GOULD, P. and WHITE, R. R. (1974) Mental Maps. Harmondsworth, Penguin.

HANSON, S. (1976) Spatial variation in the cognitive levels of urban residents, In: Spatial Choice and Spatial Behavior, R. G. Golledge and G. Rushton (Eds.). Ohio State University Press, Columbus, $\mathrm{OH}$.

HANSON, S. (1977) Measuring the cognitive levels of urban residents, Geog. Ann. B, 59, 67-81.

HEGGIE, I. G. (1977) Putting behaviour into behavioural modcls of travcl choice, J. Ops. Res. Soc., 29, 541-550.

HORTON, F. E. and REYNOLDS, D. R. (1969) An investigation of individual action spaces: a progress report, Proc. Ass. Am. Geogr., 1, 70-75.

HORTON, F. E. and REYNOLDS, D. R. (1971) Effects of urban spatial structure on individual behavior, Econ. Geogr. , 47, 36-48.

HUDSON, R. (1974) Images of the retailing environment: an example of the use of the repertory grid methodology, Envir. Behav., 6, 470-494.

JOHNSTON, R. J. (1971) Mental maps of the city: suburban preference patterns, Envir. Planning A, 3, 6372.

JOHNSTON, R. J. (1972) Activity spaces and residential preferences: some tests of the hypothesis of sectoral mental maps, Econ. Geogr., 48, 199-211.

JONES R. C. (1978) Myth maps and migration in Venezuela, Econ. Geogr., 54, 75-92.

MACKAY, D. B. (1976) The effect of spatial stimuli on the estimation of cognitive maps, Geogrl Anal., 8, 439452.

MACKAY, D. B. and OLSHAVSKY, R. W. (1975) Cognitive maps of retail locations: an investigation of some basic issues, J. Cons. Res., 2, 197-205.

MACKAY, D. B., OLSHAVSKY, R. W. and SENTELL, G. (1975) Cognitive maps and spatial behavior of consumers, Geogrl Anal., 7, 19-34.

MACLENNAN, D. and WILLIAMS, N. J. (1979) Revealed space preference theory: a cautionary note, Tijdschr. econ. soc. Geogr., 70, 307-309.

MACLENNAN, D. and WILLIAMS, J. J. (1980) Revealed-preference theory and spatial choices: some limitations, Envir. Planning A, 12,909-921.

MEYER, R. (1980) A descriptive model of constrained residential search, Geogrl Anal. 12, 21-33.

OLSHAVSKY, R. W. and MACKAY, D. B. (1975) Perceptual maps and supermarket locations, J. appl. Psychol., 60, 80 - 86.

PALMER, C. J. (1978) Understanding unbiased dimen- sions; the use of the repertory-grid methodology, Envir. Planning A, 10, 1137-1150.

PALMER, C. J., ROBINSON, M. E. and THOMAS, R. W. (1977) The countryside image: an investigation of structure and meaning, Envir. Planning A, 9, 739-749.

PIRIE, G. H. (1976) Thoughts on revealed preference and spatial behaviour, Envir. Planning A, 8, 947-955.

POTTER, R. B. (1976a) Spatial nature of consumer usage and perceptual fields, Percept. Motor Skills, 43, 11851186.

POTTER, R. B. (1976b) Directional bias within the usage and perceptual fields of urban consumers, Psychol. Rep., 38, 988-990.

POTTER, R. B. (1977a) Spatial patterns of consumer behaviour and perception in relation to the social class variable, Area, 9, 153-156.

POTTER, R. B. (1977b) The nature of consumer usage fields in an urban environment, Tijdsch econ. soc. Geogr., 68, 168-176.

POTTER, R. B. (1977c) Effects of age and family size on consumer behaviour and perception. Percept. Motor Skills, 45, 842 .

POTTER, R. B. (1978) Aggregate consumer behaviour and perception in relation to urban retailing structure: a preliminary investigation, Tijdschr. econ. soc. Geogr., 69, 345-352.

POTTER, R. B. (1979) Perception of urban retailing facilities: an analysis of consumer information fields, Geogr. Ann. B, 61, 19-29.

RECKER, W. and KOSTYNIUK, L. (1978) Factors influencing destination choice for the urban grocery shopping trip, Transportation, 7, 19-33.

RUSHTON, G. (1969) Analysis of spatial behaviour by revealed space preference, Ann. Ass. Am. Geogr., 59, $391-400$

SHEPHERD, I. D. H. and THOMAS, C. J. (1980) Urban consumer behaviour, In: Retail Geography, J. A. Dawson (Ed.). Halstead Press, New York.

SINGSON, R. L. (1975) Multidimensional scaling analysis of store image and shopping behavior, $J$. Retail., 39 , $38-52$.

SMITH, G. C. (1976) The spatial information fields of urban consumers, Trans. Inst. Br. Geogr., 1, 175-189.

SMITH, T. R., CLARK, W. A. V., HUFF, J. O. and SHAPIRO, P. (1979) A decision-making and search model for intraurban migration, Geogrl Anal., 11, 1.22.

SPENCER, A. H. (1978) Deriving measures of attractiveness for shopping centres, Reg. Stud., 12, 713-726.

SPENCER, A. H. (1980) Cognition and shopping choice: a multidimensional scaling approach, Envir. Planning A, 12, 1235-1253.

TIMMERMANS, H. J. P. (1979) A spatial preference model of regional shopping behaviour, Tijdschr. econ. soc. Geogr., 70, 45-48.

TIMMERMANS, H.J. P., HEIJDEN, R. VAN DER and WESTERVELD, H. (1981) Cognition of urban retailing structures: a Dutch case study, Tijdschr. econ. soc. Geogr. , 73, 2-12. 